\title{
The incidence of melanoma in South Africa: An exploratory analysis of National Cancer Registry data from 2005 to 2013 with a specific focus on melanoma in black Africans
}

\author{
B M Tod, ${ }^{1}$ MB BCh, MMed (Derm), FCDerm; P E Kellett, ${ }^{2}$ NDip Med Tech; E Singh, ${ }^{2}$ MB ChB, MMed (Community Health), FCPHSA \\ W I Visser, ${ }^{1} \mathrm{MB} \mathrm{ChB}, \mathrm{MFamMed}, \mathrm{MMed}$ (Derm); C J Lombard, ${ }^{3,4} \mathrm{MSc}, \mathrm{PhD}$; C Y Wright, ${ }^{5,6} \mathrm{PhD}$ \\ ${ }^{1}$ Division of Dermatology, Department of Medicine, Faculty of Medicine and Health Sciences, Stellenbosch University and Tygerberg \\ Academic Hospital, Cape Town, South Africa \\ ${ }^{2}$ National Cancer Registry, National Institute for Communicable Diseases, Johannesburg, South Africa \\ ${ }^{3}$ Division of Epidemiology and Biostatistics, Faculty of Medicine and Health Sciences, Stellenbosch University, Cape Town, South Africa \\ ${ }^{4}$ Biostatistics Unit, South African Medical Research Council, Cape Town, South Africa \\ ${ }^{5}$ Environment and Health Research Unit, South African Medical Research Council, Pretoria, South Africa \\ ${ }^{6}$ Department of Geography, Geoinformatics and Meteorology, University of Pretoria, South Africa
}

Corresponding author: B Tod (biancatod@sun.ac.za)

\begin{abstract}
Background. Melanoma is an aggressive skin cancer with poor survival when diagnosed late. There are important differences in clinical and histological features of melanoma and disease outcomes in people with darker skin types.

Methods. A retrospective review of data captured by the National Cancer Registry (NCR) of South Africa (SA) was performed for 2005 2013. Data on patient numbers, demography, location and biological features were analysed for all records. Closer analysis of melanoma of the limbs reported in black Africans was done after manually collecting this information from original reports.

Results. With 11784 invasive melanomas reported to the NCR, the overall incidence of melanoma for SA was 2.7 per 100 000. Males (51\%), individuals aged $\geq 60$ years (48\%) and the anatomical sites of lower limb (36\%) and trunk (27\%) were most commonly affected. Melanoma incidences in the white and black populations were 23.2 and 0.5 per 100000 , respectively. Most cases were diagnosed at private pathology laboratories (73\%). Superficial spreading melanoma (47\%) and nodular melanoma (20\%) predominated. Among 878 black Africans diagnosed in the public sector with melanoma of the limbs, females (68\%) and individuals aged $\geq 60$ years $(61 \%)$ were most commonly affected. Lower-limb lesions (91\%) and acral lentiginous melanoma (65\%) predominated, with $74 \%$ of cases affecting the foot and $62 \%$ of cases presenting with a Breslow depth $>4 \mathrm{~mm}$.

Conclusions. This study provides up-to-date NCR incidence and demographic data on melanoma and highlights the neglected research gaps in relation to melanoma in black Africans to provide evidence needed to address health disparities in overlooked population groups.

S Afr Med J 2019;109(4):246-253. DOI:10.7196/SAMJ.2019.v109i4.13565
\end{abstract}

The incidence of melanoma is increasing in many countries, particularly in populations with white skin. ${ }^{[1-3]}$ Australia has the highest melanoma incidence in the world, but public health campaigns have helped to stabilise the incidence in younger individuals, coupled with stabilising/reducing mortality rates in all groups apart from older males. ${ }^{[4]}$ Melanoma is an aggressive cancer when detected late. If it is diagnosed early, 5 -year survival is $>90 \%$; if it is diagnosed late, 5 -year survival is $\sim 20 \%{ }^{[3]}$

In South Africa (SA), incidence data on melanoma are limited or out of date. Studies have focused on a single population group $^{[5,6]}$ or a single province. ${ }^{[5-7]}$ Skin cancer incidence data were last reported for 2000 - 2004 (inclusive), showing differences in incidence rates and body sites by population group and gender. ${ }^{[8]}$ Melanoma is more common in fair than dark individuals, but does occur in black Africans. Since the black African group is the largest in SA, melanoma in this group has significant public health implications. ${ }^{[9]}$ While melanoma in white individuals is most commonly of the superficial spreading histological subtype and typically affects the trunk in males and the legs in females, ${ }^{[9]}$ melanoma in deeply pigmented people is more likely to be the acral lentiginous histological subtype affecting the palms and soles. ${ }^{[9-12]}$ Several studies have reported worse disease outcomes for melanoma patients with darker skin types ${ }^{[10,12,13]}$ and melanoma of hands and feet. ${ }^{[1,14]}$

\section{Objectives}

Variation in reported SA incidence rates of melanoma ${ }^{[5,7-9]}$ makes it difficult to form robust conclusions. Incidence rates ranging from 11.8 per 100000 in white females in Northern Cape Province ${ }^{[7]}$ to 69 per 100000 for the white population in Western Cape Province have been reported ${ }^{[9]}$ For black Africans, the incidence rate is about 1 per $100000 .{ }^{[9]}$ The objective of this study was to analyse and describe the most recent age-standardised melanoma incidence rates from the National Cancer Registry (NCR) by population group, gender and province in SA. Additional data were sought to inform a detailed analysis of black African individuals presenting with melanoma, specifically melanoma of the limbs (defined as shoulder to and including hand, and hip to and including foot), since there is evidence that this group of melanoma patients tends to have a worse prognosis than other melanoma patients. ${ }^{[13,14]}$ This is the first nationwide study in which detailed information, i.e. Breslow depth (BD) and stage at diagnosis, on melanoma in black South Africans has been analysed, and it will be useful to inform skin cancer awareness and screening programmes. ${ }^{[9]}$ 


\section{Methods}

\section{Study design and data}

This was a retrospective observational study of the NCR database. The NCR is a pathology-based registry that records all cancer cases diagnosed by histology or cytology in public and private healthcare laboratories throughout SA. ${ }^{[15]}$ The study examined melanoma cases reported to the NCR from 2005 to 2013 (inclusive), 2013 being the most recent year for which data were available at the time of writing, and included data from mandatory cancer reporting that was legislated in 2011 (between 2004 and 2011 some private laboratories discontinued reporting to NCR) ${ }^{[15]}$ Cancers were coded according to the International Classification of Diseases for Oncology, 3rd edition (ICD-O3), ${ }^{[16]}$ providing morphology and topography codes.

\section{Data by population group, age and anatomical site}

In a significant number of cases, the population group of patients reported to the NCR was not stated. These cases were classified by comparing their surnames with a large reference database of surnames, updated on a continuous basis, of known population groups. A hot-deck imputation method was used to assign population group to individuals. ${ }^{[8]}$

Melanoma cases were divided into age bands defined as $<40$, 40 - 59 and $\geq 60$ years of age, since melanoma is typically reported to occur in middle age, except for specific subtypes such as lentigo maligna melanoma that usually occur in older individuals. Only $2 \%$ of melanomas occur in patients aged $<2$ years. ${ }^{[3]}$ Melanomas in individuals $<40$ years of age may have unique phenotypic and genetic features. ${ }^{[17]}$ When extracting data on melanoma location, skin included all tumours coded according to the ICD-O3 as C44 (skin of various sites), C51 (skin of female genitalia), C60 (skin of male genitalia, including glans) and C63 (skin of scrotum).

\section{Incidence rates for all and by population group}

Annual melanoma incidence rates were estimated for 2005 - 2013 using at-risk mid-year population estimates from updated 2005 2013 mid-year population estimates in the 2017 mid-year population data (provided by Prof. Rob Dorrington of the Centre for Actuarial Research at the University of Cape Town). Annual incidence rates were standardised against a World Health Organization world population using age. For those patients who could not be assigned a population group based on the aforementioned hot-deck approach, missing data were distributed proportionally to the observed distribution for incidence estimates for year and population group. Data were prepared in Excel 2013 (Microsoft, USA) and analysed using Stata 14 (StataCorp, USA).

\section{Additional data analysed specifically for black Africans}

The NCR manually extracted additional data on each case for black African patients only, diagnosed with melanoma of the limbs from 2005 to 2013 from NCR public National Health Laboratory Service (NHLS) data. Data on NHLS patients were more readily available than data on private patients. Patients with ICD-O3 topography codes C44.6 (skin of upper limb, shoulder) and C44.7 (skin of lower limb, hip) were extracted. An attempt was made to ascertain exact anatomical site, BD and stage of disease by closer examination of reports.

\section{Anatomical site, Breslow depth and staging}

Owing to large detail variations from one pathology report to another, 'hand' was taken to include nonspecific 'hand' or anything indicating involvement of finger or palmar skin. Lesions clearly involving the dorsum of the hand were included in the 'other' group. A similar approach was made for foot and plantar skin. The 'other' group included lesions involving the dorsum of the hand and foot as well as more distant sites, i.e. elbow/knee. Only when clearly documented to involve the nail was the lesion included in the 'nail' group.

$\mathrm{BD}$ measurements were grouped according to the accepted pathological staging of tumour $(\mathrm{T})$ component with $\mathrm{T} 1 \leq 1.0 \mathrm{~mm}$, $\mathrm{T} 2=1.01-2.0 \mathrm{~mm}, \mathrm{~T} 3=2.01-4.0 \mathrm{~mm}$ and $\mathrm{T} 4>4.0 \mathrm{~mm} \cdot{ }^{[3]}$ Clark depth according to the American Joint Committee on Cancer staging system was captured..$^{[3]}$

Disease stage was recorded according to pathologist diagnosis when clinical or pathological staging was available. Staging was according to the TNM Classification of Malignant Tumors, ${ }^{[3]}$ and where only limited data were available (e.g. 'metastasised'), this was also recorded.

\section{Ethics approval}

Ethics approval was obtained from the Stellenbosch University Health Research Ethics Committee (ref. no. N15/12/129A).

\section{Results}

\section{Sample description and annual melanoma incidence} rates in all population groups

A total of 11784 invasive (i.e. excluding in situ) melanomas were reported to the NCR for 2005 - 2013 (inclusive). Of these, 5727 (49\%) occurred in females and 6049 (51\%) in males (in 8 cases sex was unknown) (male/female gender ratio 1:0.9). A total of 1801 melanomas (15\%) were recorded in the age group <40 years, 4178 (35\%) in the age group 40 - 59 years and $5662(48 \%)$ in the age group $\geq 60$ years. Melanoma frequencies were highest in the white group ( $n=8$ 104), followed by 1991 melanomas in black Africans, 1070 in coloured individuals (of mixed ancestry) and 106 in Indians/Asians. In 513 cases population group was unknown. The incidence of melanoma for SA was 2.6 per 100000 (Table 1). A striking dip in the number of cases reported in 2009 and 2010 was probably related to underreporting from private laboratories prior to 2011 . When post-2011 data were used, the national melanoma incidence was 2.7 per 100000 .

Western Cape and Gauteng provinces had the highest melanoma incidence rates, followed by the Northern Cape (Table 2). Nearly 75\% of all melanomas in all population groups were diagnosed in private laboratories (Table 1), while $75 \%$ of melanomas in black Africans were diagnosed in the public sector.

Ninety-six percent $(n=11266)$ of melanomas primarily involved the skin and $518(4 \%)$ involved extracutaneous sites (including ocular, mucosal, central nervous system and 'unknown primary site'). Of cutaneous melanomas, 4247 (38\%) were reported as 'Skin, not otherwise specified (NOS)'. Fig. 1 shows the percentage involvement of body areas by cutaneous melanoma for all population groups. For extracutaneous melanoma (Table 3), 'Other sites' refers to diverse areas (from lung to colon), probably owing to metastatic disease and possibly instances of misreporting. Ocular melanoma could not be classified into conjunctival, uveal tract and other ocular sites owing to existing divisions of the ICD-O3 coding system (Table 4). Morphological descriptions (Table 5) show a low frequency of mucosal lentiginous melanomas $(0.03 \%)$ (morphology code) v. a higher frequency reported at mucosal sites ( $0.5 \%)$ (topography code), probably owing to variations in reporting detail and the fact that not all mucosal melanomas have this specific morphology.

Where specific histological subtype was recorded, superficial spreading melanoma predominated with $47 \%$ cases, followed by nodular $(20 \%)$, acral lentiginous (11\%) and lentigo maligna melanoma (9\%). 


\begin{tabular}{|c|c|c|c|c|c|c|c|c|c|c|c|}
\hline & 2005 & 2006 & 2007 & 2008 & 2009 & 2010 & 2011 & 2012 & 2013 & $\begin{array}{l}\text { All } 2005 \text { - } \\
2013\end{array}$ & $\begin{array}{l}\text { All } 2011 \text { - } \\
2013\end{array}$ \\
\hline \multicolumn{12}{|l|}{ Annual incidence rates, } \\
\hline All & 2.9 & 2.8 & 2.6 & 2.6 & 2.0 & 2.0 & 2.6 & 2.8 & 2.9 & 2.6 & 2.7 \\
\hline \multicolumn{12}{|l|}{ Gender } \\
\hline Male & 3.2 & 2.9 & 2.7 & 2.8 & 2.0 & 2.2 & 2.8 & 2.8 & 3.1 & 2.7 & 2.9 \\
\hline Female & 2.7 & 2.6 & 2.4 & 2.4 & 2.0 & 1.9 & 2.4 & 2.7 & 2.6 & 2.4 & 2.6 \\
\hline \multicolumn{12}{|l|}{ Population group } \\
\hline Black African & 0.6 & 0.6 & 0.6 & 0.6 & 0.6 & 0.4 & 0.5 & 0.6 & 0.5 & 0.5 & 0.5 \\
\hline Coloured & 2.7 & 3.0 & 2.6 & 2.7 & 2.2 & 2.2 & 2.9 & 3.0 & 2.9 & 2.7 & 2.9 \\
\hline Indian/Asian & 0.9 & 0.8 & 1.2 & 1.2 & 0.4 & 0.7 & 1.0 & 0.9 & 1.3 & 0.9 & 1.1 \\
\hline White & 22.1 & 20.8 & 19.2 & 19.6 & 14.5 & 16.2 & 21.0 & 23.0 & 25.5 & 20.2 & 23.2 \\
\hline \multicolumn{12}{|l|}{ Age group (years) } \\
\hline$\leq 39$ & 0.7 & 0.6 & 0.6 & 0.6 & 0.3 & 0.4 & 0.5 & 0.4 & 0.4 & 0.5 & 0.4 \\
\hline $40-59$ & 6.0 & 5.8 & 5.3 & 4.9 & 4.2 & 4.3 & 4.8 & 5.4 & 5.4 & 5.1 & 5.2 \\
\hline$\geq 60$ & 18.0 & 17.7 & 15.9 & 17.2 & 13.4 & 13.0 & 18.2 & 18.6 & 20.1 & 16.9 & 19.0 \\
\hline \multicolumn{12}{|l|}{ Counts by year, $n$} \\
\hline \multicolumn{12}{|l|}{ Public v. private } \\
\hline NHLS counts & 379 & 313 & 357 & 367 & 381 & 322 & 335 & 396 & 323 & 3173 & 1054 \\
\hline Private counts & 1032 & 1036 & 915 & 928 & 645 & 735 & 1026 & 1075 & 1219 & 8611 & 3320 \\
\hline $\begin{array}{l}\text { Black Africans diagnosed } \\
\text { with melanoma of the limb }\end{array}$ & 112 & 106 & 115 & 53 & 53 & 75 & 126 & 130 & 108 & 878 & - \\
\hline
\end{tabular}

Table 2. Annual incidence rates for melanoma by South African province, $2011-2013^{*}$

\begin{tabular}{|c|c|c|c|c|c|c|}
\hline \multirow[b]{2}{*}{ Province } & \multirow[b]{2}{*}{ Capital city latitude } & \multicolumn{4}{|c|}{ Annual incidence rates, /100 000} & \multirow{2}{*}{$\begin{array}{l}\text { Black Africans in NHLS with } \\
\text { melanoma (2005 - 2013), } n(\%)\end{array}$} \\
\hline & & $2011^{\dagger}$ & 2012 & 2013 & All 2011 - 2013 & \\
\hline Eastern Cape & $\begin{array}{l}\text { Bhisho } \\
32^{\circ} 50^{\prime} \mathrm{S}\end{array}$ & 1.9 & 2.1 & 1.8 & 1.9 & $158(18)$ \\
\hline Free State & $\begin{array}{l}\text { Bloemfontein } \\
29^{\circ} 5^{\prime} \mathrm{S}\end{array}$ & 2.9 & 3.4 & 4.0 & 3.4 & $90(10)$ \\
\hline Gauteng & $\begin{array}{l}\text { Johannesburg } \\
26^{\circ} 12^{\prime} \mathrm{S}\end{array}$ & 4.3 & 4.3 & 4.6 & 4.4 & $233(26)$ \\
\hline KwaZulu-Natal & $\begin{array}{l}\text { Pietermaritzburg } \\
29^{\circ} 36^{\prime} \mathrm{S}\end{array}$ & 0.7 & 0.7 & 0.7 & 0.7 & $97(11)$ \\
\hline Limpopo & $\begin{array}{l}\text { Polokwane } \\
23^{\circ} 53^{\prime} \mathrm{S}\end{array}$ & 0.8 & 0.9 & 0.4 & 0.7 & $115(13)$ \\
\hline Mpumalanga & $\begin{array}{l}\text { Nelspruit } \\
25^{\circ} 28^{\prime} \mathrm{S}\end{array}$ & 1.2 & 0.9 & 1.1 & 1.1 & $69(7)$ \\
\hline Northern Cape & $\begin{array}{l}\text { Kimberley } \\
28^{\circ} 43^{\prime} \mathrm{S}\end{array}$ & 3.9 & 5.4 & 5.7 & 5.0 & $15(1)$ \\
\hline North West & $\begin{array}{l}\text { Mahikeng } \\
25^{\circ} 51^{\prime} \mathrm{S}\end{array}$ & 0.3 & 0.6 & 0.6 & 0.5 & $56(6)$ \\
\hline Western Cape & $\begin{array}{l}\text { Cape Town } \\
33^{\circ} 55^{\prime} \mathrm{S}\end{array}$ & 6.8 & 7.5 & 8.0 & 7.5 & $45(5)$ \\
\hline
\end{tabular}

\section{Melanoma on the limbs in black Africans in the public sector}

Melanoma in black Africans ( $n=1991$ ) occurred mostly in the skin (92\%) and to a lesser extent in mucosa, ocular and other/extracutaneous/unknown sites. Fig. 2 shows the percentage involvement of body areas by cutaneous melanoma in all black African patients.
Of all the melanomas occurring on the limbs in all population groups, $27 \%$ originated in black Africans.

A total of 878 black Africans were diagnosed with melanoma of the limbs (68\% were female and $32 \%$ were male; in 3 cases sex was unknown). The majority were aged $\geq 60$ years $(n=515,61 \%)$ followed by ages $40-59$ years $(n=268,32 \%)$ and $<40$ years $(n=62,7 \%)$. The 
highest number of melanomas of the limbs in black Africans was diagnosed in Gauteng $(n=233,27 \%)$, followed by the Eastern Cape $(n=158,18.0 \%)$ and Limpopo $(n=115,13 \%)$ (Table 2). Other provinces had $<100$ cases each.

Of black Africans diagnosed with limb melanoma, fewer $(n=81,9 \%)$ were coded as having melanomas with topography codes of C44.6 (upper limb) than melanomas of the lower limb ( $n=797,91 \%)$ (code C44.7).
Specific locations were highest for the foot ( $n=652,74 \%)$ followed by other areas of the limb $(n=84,10 \%)$, the hand $(n=47,5 \%)$, the nail apparatus $(n=15,2 \%)$ and unknown sites $(n=80,9 \%)$. Relative frequencies of pathological (morphological) subtypes of melanoma reported in black Africans with melanoma of limbs are set out in Table 6. After excluding the NOS code, $65 \%$ of melanomas were acral lentiginous melanomas and $10 \%$ were nodular melanomas.

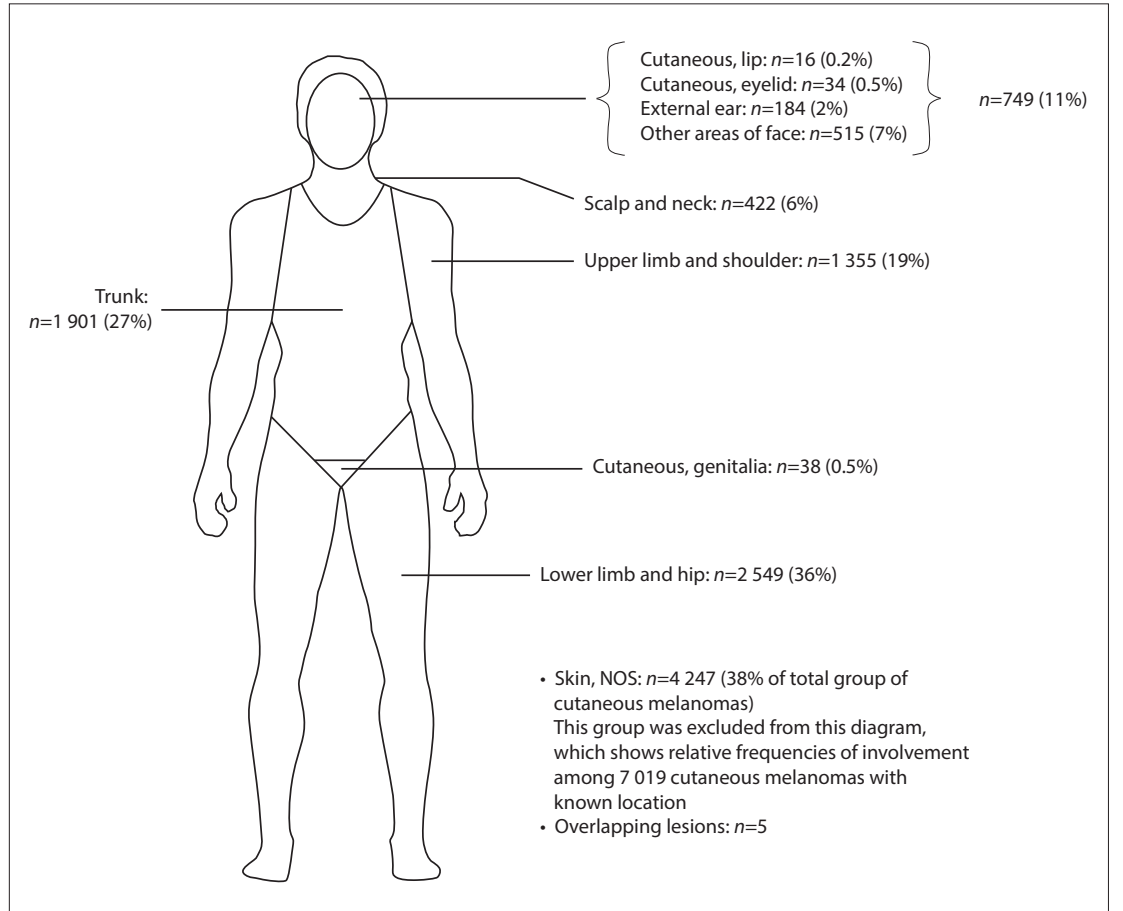

Fig. 1. Distribution of melanoma incidence as a frequency count (and as a percentage of all body sites in parentheses) by anatomical site for all population groups. (NOS = not otherwise specified.)
$\mathrm{BD}$ was recorded in 347 cases of melanoma of the limbs (39\%) in black Africans. In the majority, BD was $>4 \mathrm{~mm}(n=222,64 \%)$, followed by $2.01-4 \mathrm{~mm}(n=75,22 \%)$ and then $1.01-2 \mathrm{~mm}(n=30,9 \%)$ and $<1 \mathrm{~mm}$ $(n=20,6 \%)$. The largest BD recorded was $95 \mathrm{~mm}$. Distribution of BDs was fairly similar for upper- and lower-limb lesions. Each group tended to present late with large BDs, so for the upper limb $72 \%$ presented with BDs $>4 \mathrm{~mm}$, and for the lower limb $62 \%$ presented with BDs $>4 \mathrm{~mm}$. Similarly, where Clark level was known, patients mainly presented with Clark levels IV and $\mathrm{V}$ (85\% of those with known Clark level). Staging information was only available for 86 patients. Of these, partial staging was stated in 7 patients, 26 were in stage I or II, and 53 were in stage III, IV, 'advanced' or 'metastasised'.

\section{Discussion}

The national melanoma incidence rate based on cases reported to the NCR was $<3$ per 100000 , with men having a slightly higher incidence than women. This figure is lower than the previous study (mean age-standardised annual incidence for the population as a whole of 5.3 per 100000 for men and 3.9 per 100000 for women): ${ }^{[8]}$ however, this change must be interpreted with care as it probably does not reflect a true reduction in incidence. Incomplete case reporting to the NCR is possibly responsible, and factors such as a small population reduction in the percentage of whites (who are more likely to experience melanoma than other groups) in the population as a whole

Table 3. Relative frequencies of extracutaneous melanoma, 2005 - 2013

\begin{tabular}{llll}
\hline & Frequency $(\boldsymbol{N = 1 1 ~ 7 8 4}), \boldsymbol{n}$ & $\%$ & \% after exclusion of cutaneous melanomas $(\boldsymbol{N}=\mathbf{5 1 8})$ \\
\hline Eye and ocular apparatus & 127 & 1 & 24 \\
Central nervous system & 2 & 0.02 & 0.3 \\
Mucosal sites & 67 & 0.5 & 12 \\
Other sites* & 322 & 3 & 62 \\
*'Other sites' refers to diverse organs ranging from the lung to the colon, probably representing metastatic disease. It also includes lesions designated as 'Unknown primary site.'
\end{tabular}

Table 4. Relative frequencies of eye and ocular apparatus involvement, 2005 - 2013 (excludes eyelids)

Conjunctiva
Cornea, NOS; limbus of cornea
Retina
Choroid ${ }^{*}$
Ciliary body, crystalline lens, iris, sclera, uveal tract, intraocular, eyeball
Orbit, NOS; autonomic nervous system of orbit; connective tissue of orbit, extraocular
muscle, peripheral nerves of orbit, retrobulbar tissue, soft tissue of the orbit
Eye, NOS
${ }^{*}$ Nos $=$ not otherwise specified.

\begin{tabular}{ll} 
Frequency $(\boldsymbol{N = 1 1} \mathbf{7 8 4}), \boldsymbol{n}$ & Ocular lesions, \% \\
\hline 24 & 19 \\
2 & 2 \\
1 & 0.7 \\
22 & 17 \\
14 & 11 \\
5 & 4 \\
59 & \\
& 46
\end{tabular}


Table 5. Relative frequencies of pathological (morphological) subtypes of melanoma, 2005 - 2013

\begin{tabular}{llll}
\hline Morphological description & $\begin{array}{l}\text { Frequency } \\
(\mathbf{N = 1 1 7 8 4}), \boldsymbol{n}\end{array}$ & $\mathbf{\%}$ & $\begin{array}{l}\text { \% after exclusion of NOS } \\
\text { code }(\mathbf{N = 5 0 6 3})\end{array}$ \\
\hline Malignant melanoma, NOS (except juvenile melanoma) & 6721 & 57 & - \\
Superficial spreading melanoma & 2366 & 20 & 47 \\
Nodular melanoma & 1005 & 9 & 20 \\
Acral lentiginous melanoma & 555 & 5 & 11 \\
Lentigo maligna melanoma & 449 & 4 & 9 \\
Epithelioid cell melanoma & 199 & 2 & 4 \\
Amelanotic melanoma & 149 & 1 & 3 \\
Spindle cell melanoma, NOS & 137 & 1 & 3 \\
Mixed epithelioid and spindle cell melanoma & 85 & 0.7 & 2 \\
Desmoplastic melanoma & 47 & 0.4 & 0.9 \\
Malignant melanoma in a giant pigmented naevus & 18 & 0.1 & 0.3 \\
Malignant melanoma in junctional naevus & 17 & 0.1 & 0.3 \\
Spindle cell melanoma, type B & 14 & 0.1 & 0.2 \\
Malignant melanoma, regressing & 6 & 0.1 & 0.1 \\
Malignant melanoma in precancerous melanosis & 5 & 0.04 & 0.1 \\
Blue naevus, malignant & 5 & 0.04 & 0.1 \\
Balloon cell melanoma & 3 & 0.03 & 0.06 \\
Mucosal lentiginous melanoma & 3 & 0.03 & 0.06 \\
NOS = not otherwise specified. & & &
\end{tabular}

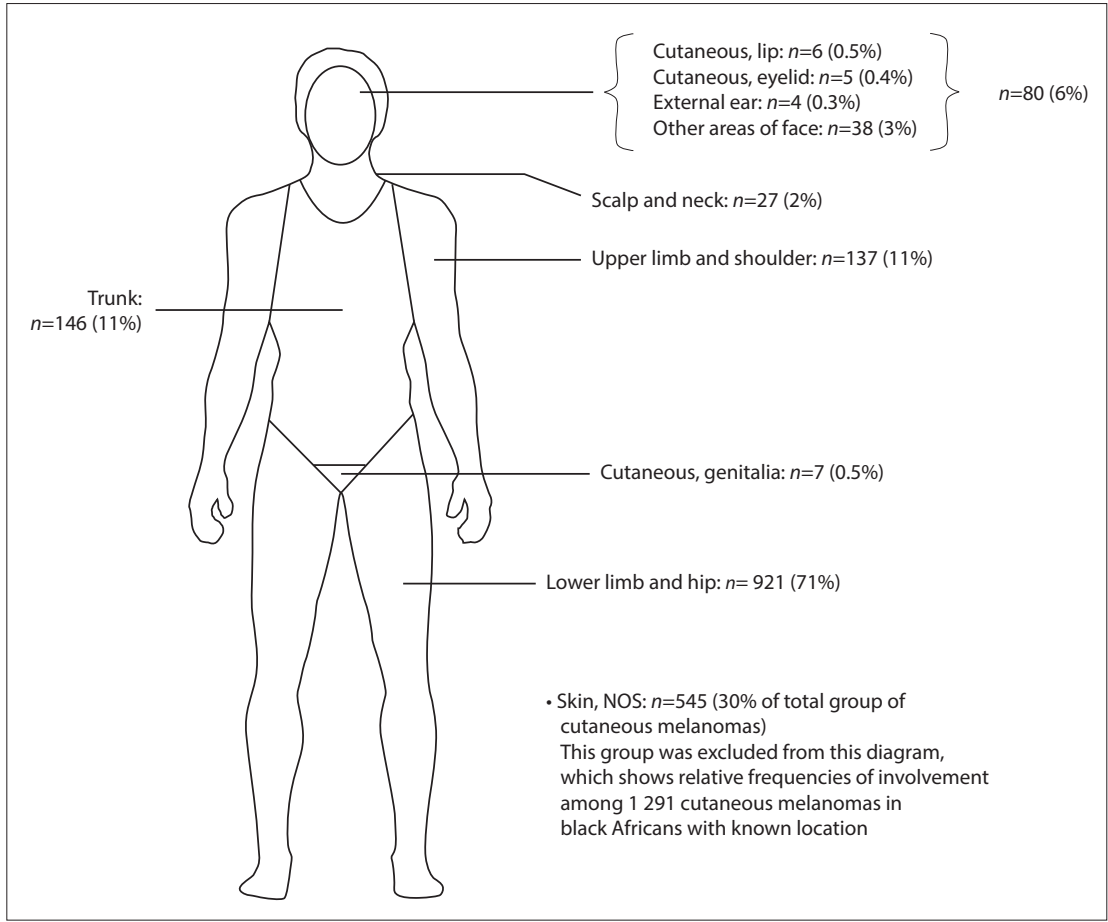

Fig. 2. Distribution of melanoma incidence as a frequency count (and as a percentage of all body sites in parentheses) by anatomical site for the black African population group. (NOS = not otherwise specified.)

between 2005 (when white individuals comprised $9.3 \%$ of SA's population) and 2013 (8.7\%) may have contributed. ${ }^{[18,19]}$ Ongoing analysis of NCR numbers and external validation are needed to confirm these numbers.

The typical trend of increasing melanoma incidence in older patients was evident, with the highest incidence rates observed in the $\geq 60$-year-old group. ${ }^{[8,20]}$ The elderly represent an important age group for screening, but clinicians should aim to diagnose melanoma in its in situ phase whenever possible, so ideally screening should start earlier. Annual melanoma screening is justified in individuals between 35 and 75 years of age if the individual has one or more risk factors for melanoma ${ }^{[21]}$ and may be feasible in SA, but depends highly on affordability and healthcare access.

There is some evidence to suggest a slight increase in melanoma incidence in the white group compared with the previous study, ${ }^{[8]}$ but this differs from other previous studies of melanoma incidence in white individuals in Cape Town, and again must be interpreted with caution. ${ }^{[5,6]}$ Comparing study findings is difficult owing to different methodologies and populations of interest. The Western Cape data showed high incidences in whites (33.5 per 100000 in females and 36.9 per 100000 in males for 2001 - 2003) in Cape Town. ${ }^{[6]}$ The Northern Cape study found incidence rates for $2008-2012$ of $<20$ per 100000 for Whites. ${ }^{[7]}$ These regional studies used pathology data, which may have improved accuracy, but their conclusions cannot be generalised.

It is interesting to consider that the incidence rate of melanoma for white South Africans is less than half that reported in Australia (72 per 100000 in 2010 - 2014 for the entire population), ${ }^{[4]}$ as there are likely to be similarities in lifestyle among white individuals living in the two countries. Differences may arise from different thresholds for classifying grey-area lesions (severely dysplastic naevus v. melanoma) as melanomas, ${ }^{[4]}$ missed reporting to the NCR, an increased prevalence of risk factors in Australia, or a combination of these or other factors.

Each population has its own profile and prevalence of individual melanoma risk factors such as number of naevi per 
Table 6. Relative frequencies of pathological (morphological) subtypes of melanoma reported in the black African population group with melanoma of the limbs, 2005 - 2013

\begin{tabular}{|c|c|c|c|}
\hline Morphological description & $\begin{array}{l}\text { Frequency } \\
(N=878), n\end{array}$ & $\%$ & $\begin{array}{l}\% \text { after exclusion of NOS } \\
\text { code }(N=493)\end{array}$ \\
\hline Malignant melanoma, NOS (except juvenile melanoma) & 385 & 44 & - \\
\hline Acral lentiginous melanoma & 321 & 37 & 65 \\
\hline Nodular melanoma & 48 & 5 & 10 \\
\hline Epithelioid cell melanoma & 39 & 4 & 8 \\
\hline Spindle cell melanoma, NOS & 24 & 3 & 5 \\
\hline Mixed epithelioid and spindle cell melanoma & 20 & 2 & 4 \\
\hline Superficial spreading melanoma & 15 & 2 & 3 \\
\hline Amelanotic melanoma & 13 & 1 & 3 \\
\hline Desmoplastic melanoma & 4 & 0.4 & 0.8 \\
\hline Malignant melanoma in a giant pigmented naevus & 4 & 0.4 & 0.8 \\
\hline Lentigo maligna melanoma & 3 & 0.3 & 0.6 \\
\hline Blue naevus, malignant & 1 & 0.1 & 0.2 \\
\hline Malignant melanoma in junctional naevus & 1 & 0.1 & 0.2 \\
\hline
\end{tabular}

individual and family history of melanoma ${ }^{[22]}$ and unique geographical features. ${ }^{[23]}$ No in-depth analysis exists comparing melanoma risk profiles of South Africans and Australians. Australia's population comprises about $90 \%$ white citizens by informal estimates, ${ }^{[24]}$ although it is impossible to quote an exact percentage as Australia's census does not collect ethnicity data in this way. ${ }^{[25]}$

With regard to other population groups, the reason for the slight decline in the incidence among black Africans compared with earlier studies is unclear. Missed cases may be the cause. Changes have also occurred in the demography of black Africans, where international immigrants comprise $4.2 \%$ of the population and $75.5 \%$ of immigrants come from other African countries. ${ }^{[26]}$ Although the NCR makes every effort to only include SA residents' data, some nonSA citizens may be included.

Differences in melanoma incidence by province in which diagnoses were made may be influenced by the population group ratios, which differ by province. Gauteng and the Western Cape were home to 1913886 and 915055 white citizens, respectively, of a total of 4586838 white South Africans at the 2011 census. ${ }^{[27]}$ These provinces are probably important sites for patient and professional melanoma education, but patients may also have travelled from other provinces to seek dermatology services in large cities, so nationwide melanoma education is still important.

While the Western Cape is far south, ${ }^{[28]}$ there are other potentially confounding factors (e.g. lifestyle choices such as tanning) that may be responsible for the higher incidence observed in Cape Town compared with Johannesburg, in Gauteng. No association was observed in melanoma incidence variation from province to province by latitude, but provincial population group proportions and other confounders were not taken into account.

Nearly $75 \%$ of all melanoma cases originated in the private sector. These were all invasive melanomas and therefore unlikely to be due to 'over-representation' of early diagnoses. This discrepancy is probably related to divisions of healthcare (private v. public) by population group. A sizeable proportion (75\%) of black African patients with melanoma were diagnosed in the state sector (probably because fewer black Africans than whites have medical insurance), ${ }^{[29]}$ demonstrating that teaching about melanoma is important for healthcare providers in both sectors.

With regard to anatomical distribution of melanoma, lesions of the lower limb and hip were most common, followed by truncal lesions, then upper limb and shoulder lesions and finally those of head and neck. Typically truncal lesions were most common in white males, who generally had the highest incidence. ${ }^{[3,30]}$ This is probably due to the relatively large population of black Africans in SA frequently developing melanoma on the limbs, particularly the lower limbs, and the fact that melanomas of the leg are typically reported to be more common in white females (we did not examine this specifically). ${ }^{[8]}$

A unique aspect of this study was the detailed analysis of reports specifically for black Africans. Where morphology was known, acral lentiginous melanoma predominated, which was not surprising as other studies have also found this the most common type of melanoma among deeply pigmented individuals. ${ }^{[31,32]}$ Representation of other histological subtypes suggests that not all hand and foot melanomas conform to the acral lentiginous histological subtype. ${ }^{[1]}$

The male/female ratio among black Africans with limb melanoma showed a significant female preponderance. Previous studies of acral melanoma have observed a female preponderance in both South African ${ }^{[33]}$ and other population groups. ${ }^{[32]}$ Similar to all population groups, black Africans tended to be $\geq 60$ years old, as reported in other SA studies. ${ }^{[34,35]}$

A predominance of lesions of the lower limb and foot was identified in black Africans. The hand/foot ratio of close to 1:13 was similar to a previous systematic review reporting a hand/foot ratio of between 1:13 and 1:3-1:4. ${ }^{[11]}$ While there is a strong perception that melanoma does not occur in deeply pigmented individuals, our study showed that $\sim 17 \%$ of melanomas occurred in black Africans. Just over $80 \%$ of these patients had limb melanomas, which would include (but are not exclusive to) melanoma of the palms, soles and nail beds. A large proportion of cases were coded as 'Skin, NOS'; however, 146 were reported on the trunk and 80 on the head and neck, refuting the notion that black African patients do not develop melanomas at these sites. With regard to mucosal melanomas, 33 of 67 of these lesions occurred in black Africans, slightly higher than expected as the incidence of mucosal melanoma in white individuals has been reported as being twice that in black individuals. ${ }^{[36]}$

It is recognised that melanoma behaves differently, is less common and has a poorer prognosis (often with late-stage presentation) in deeply pigmented individuals. ${ }^{[10,13]} \mathrm{BD}$ is considered the single most important prognostic factor for melanoma, ${ }^{[3]}$ yet only $39 \%$ of pathology reports analysed in the present study contained a $\mathrm{BD}$. Where $\mathrm{BD}$ was available it was $>4 \mathrm{~mm}$ in most cases, conferring a 
poor prognosis. The deepest $\mathrm{BD}$ of $95 \mathrm{~mm}$ was striking, suggesting a large, neglected tumour. Presentation with large BDs is an indicator of missed opportunities where patients should have been diagnosed earlier. While not possible with our data, it would have been interesting to perform an inter-population group comparison of BD to find out whether or not white patients were diagnosed earlier. One would expect them to be, since medical practitioners are anecdotally considered to be aware of the danger of melanoma in whites, and there are inherent challenges in diagnosing melanoma in darker skin types. ${ }^{[10]} \mathrm{A}$ recent study documenting a cohort of 66 SA patients with acral melanoma demonstrated higher BDs in black patients than in other population groups. ${ }^{[33]}$

Staging data were extremely limited, and it was difficult to make robust conclusions. There is probably also a bias towards reporting of late staging, as this is often only definitive with pathology specimen submission when metastatic disease is apparent.

\section{Study limitations}

Our study was novel in reporting detailed information on BD and stage at diagnosis among black South Africans; however, several limitations were noted. Within the scope of the study, a manual exercise to search original records was done specifically for cases of melanoma of the limbs in black Africans in the public sector, but not for any other groups or melanoma types owing to the scale of this task. Melanoma of the limbs in black Africans was chosen because it has been reported as the most common melanoma type in deeply pigmented patients and is associated with a poor prognosis. ${ }^{[10,34]}$

It must be noted that under-reporting to the NCR is still likely, and there is no control in place to confirm accuracy. Future monitoring and analysis are mandatory to validate these outcomes. It cannot be assumed that these numbers reflect accurate incidence rates - they merely provide an early estimate that needs to be followed up and validated. There may still be melanoma cases that were missed (e.g. where diagnoses were not confirmed with pathology). Despite success of mandatory cancer reporting, pathology-based registries have innate limitations. Cancers diagnosed based on clinical examination alone or radiology (without histology), for example, will not be included. However, it would be unusual for melanoma to be diagnosed in this way. The effect of reduced reporting prior to 2011 is an important bias that we tried to overcome by reporting the incidence for post-2011. Time must be allowed for data collection by the NCR to stabilise.

Another limitation when reporting numbers of patients referred by private and public laboratories is that laboratories in academic centres may receive specimens as referrals from private laboratories when there are difficulties with diagnosis. Similarly, interprovincial referral of specimens may occur, but systems are in place to exclude duplications as well as to handle incomplete information.

While the NCR does not collect data on in situ lesions, this is in line with the approach of other registries. ${ }^{[14]} \mathrm{A}$ limitation is exclusion of very poorly differentiated tumours that could not be categorised as melanoma. The ICD-O topographical divisions were too broad to completely satisfy an investigation of acral melanoma in black African patients.

The frequency of NOS codes, while a relief for time-strapped healthcare workers, results in a blind spot. Pathology reporting on melanomas should be more detailed and standardised; for example, reporting on precise location, $\mathrm{BD}$, presence/absence of metastatic disease and comorbidities would be optimal. Follow-up data on disease progression and survival are essential to provide a more complete picture of the impact of melanoma. Future analyses may show that increases in incidence are due to an increase in diagnosis of thinner melanoma, as observed elsewhere, ${ }^{[6]}$ an indicator of success of education programmes provided by the Cancer Association of South Africa, medical professionals and other healthcare providers.

\section{Conclusions}

This study has provided a basis for obtaining more accurate melanoma incidence data and monitoring changes in incidence rates. It highlights melanoma in black Africans, emphasising that it is a significant public health problem, particularly because of late diagnosis. The findings are important to increase physician awareness and to strengthen public health education for melanoma primary and secondary prevention in SA.

\section{Declaration. None.}

Acknowledgements. The authors thank the NCR for the data used in this study. The updated 2017 mid-year population estimates for the years of the study were provided by Prof. Rob Dorrington from the Centre of Actuarial Research at the University of Cape Town. The 2011 census population group and province data were provided by Chantal Munthree of Statistics South Africa. We also thank Prof. Adele Green from the QIMR Berghofer Medical Research Institute for assisting with the Australian incidence rates and population group data. Finally, we thank Prof. Mary Norval of the University of Edinburgh for her review and comments on an earlier draft of the manuscript.

Author contributions. BMT: design, manuscript preparation, editing, administration; PEK, ES: access to and extraction and interpretation of data from NCR database, editing; WIV: editing; CJL: statistical analysis and interpretation; CYW: manuscript preparation and editing.

Funding. CYW receives funding from the South African Medical Research Council and the National Research Foundation of South Africa.

Conflicts of interest. None.

1. Nikolaou V, Stratigos AJ. Emerging trends in the epidemiology of melanoma. Br J Dermato 2014;170(1):11-19. https://doi.org/10.1111/bjd.12492

2. National Cancer Institute. Surveillance Epidemiology and End Results Program. Cancer statistics facts: Melanoma of the skin. https://seer.cancer.gov/statfacts/html/melan.html (accessed 23 March 2018). Melanoma of the skin. https://seer.cancer.gov/statfacts/html/melan.html (access

4. Aitken JF, Youlden DR, Baade PD, Soyer HP, Green AC, Smithers BM. Generational shift in melanoma 4. Aitken JF, Youlden DR, Baade PD, Soyer HP, Green AC, Smithers BM. Generational shift in melanoma
incidence and mortality in Queensland, Australia, 1995 - 2014. Int J Cancer 2018;142(8):1528-1535. incidence and mortality in Queens
https://doi.org/ $10.1002 /$ ijc.31141

5. Saxe N, Hoffman M, Krige JE, Sayed R, King HS, Hounsell K. Malignant melanoma in Cape Town, South Africa. Br J Dermatol 1998;138(6):998-1002.

6. Jessop S, Stubbings H, Sayed R, Duncan-Smith J, Schneider J, Jordaan H. Regional clinical registry data show increased incidence of cutaneous melanoma in Cape Town. S Afr Med J 2008;98(3):197-199.

7. York K, Dlova NC, Wright CY, et al. Primary cutaneous malignancies in the Northern Cape Province of South Africa: A retrospective histopathological review. S Afr Med J 2017;107(1):83-88. https://doi. org/10.7196/SAMJ.2016.v107.11.10924

8. Norval M, Kellett P, Wright CY. The incidence and body site of skin cancers in the population groups of South Africa. Photodermatol Photoimmunol Photomed 2014;30(5):262-265. https://doi.org/10.1111/ phpp. 12106

9. Norval M, Wright CY. The epidemiology of cutaneous melanoma in the white and black African population groups in South Africa. In: Ward WH, Farma JM, eds. Cutaneous Melanoma: Etiology population groups in South Africa. In: Ward WH, Farma JM, eds. Cutaneous Melanoma: Etiology
and Therapy. Brisbane: Codon Publications, 2017:23-38. https://www.ncbi.nlm.nih.gov/books/ and Therapy. Brisbane: Codon Publica.

10. Mahendraraj K, Sidhu K, Lau CSM. Malignant melanoma in African Americans. Medicine (Baltimore) 2017;96(15):e6258-e6266. https://doi.org/10.1097/MD.0000000000006258

11. Durbec F, Martin L, Derancourt C, Grange F. Melanoma of the hand and foot: Epidemiological, prognostic and genetic features: A systematic review. Br J Dermatol 2012;166(4):727-739. https://doi. org/10.1111/j.1365-2133.2011.10772.x

12. Bradford PT, Goldstein AM, Mcmaster ML, Tucker MA. Acral lentiginous melanoma: Incidence and survival patterns in the United States, 1986 - 2005. Arch Dermatol 2009;145(4):427-434. https://doi. org/10.1001/archdermatol.2008.609

3. Dawes SM, Tsai S, Gittleman H, Barnholtz-Sloan JS, Bordeaux JS. Racial disparities in melanoma survival. JAMA Dermatol 2016;75(5):983-991. https://doi.org/10.1016/j.jaad.2016.06.006

14. Teramoto Y, Keim U, Gesierich A, et al. Acral lentiginous melanoma - a skin cancer with unfavourable prognostic features: A study of the German Central Malignant Melanoma Registry (CMMR) in 2050 patients. Br J Dermatol 2018;178(2):443-451. https://doi.org/10.1111/bjd.15803

15. Singh E, Underwood JM, Nattey C, Babb C, Sengayi M, Kellett P. South African National Cancer Registry: Effect of withheld data from private health systems on cancer incidence estimates. S Afr Med J 2015;105(2):107-109. https://doi.org/10.7196/SAMJ.8858

16. Fritz A, Percy C, Jack A, et al., eds. International Classification of Diseases for Oncology. 3rd ed. Geneva: World Health Organization, 2013. http://codes.iarc.fr/ (accessed 27 February 2019). 
17. Tricoli JV, Blair DG, Anders CK, et al. Biologic and clinical characteristics of adolescent and young adult cancers: Acute lymphoblastic leukemia, colorectal cancer, breast cancer, melanoma, and sarcoma. adult cancers: Acute lymphoblastic leukemia, colorectal cancer, brest

18. Statistics South Africa. Mid-year population estimates, South Africa 2005. Statistical release P0302 2005. http://www.statssa.gov.za/publications/P0302/P03022005.pdf (accessed 31 May 2018).

19. Statistics South Africa. Mid-year population estimates 2013. http://www.statssa.gov.za/publications P0302/P03022013.pdf (accessed 31 May 2018).

20. Apalla Z, Lallas A, Sotiriou E, Lazaridou E, Ioannides D. Epidemiological trends in skin cancer. Dermatol Pract Concept 2017;7(2):1-6. https://doi.org/10.5826/dpc.0702a01

21. Johnson MM, Leachman SA, Aspinwall LG, et al. Skin cancer screening: Recommendations for data-driven screening guidelines and a review of the US Preventive Services Task Force controversy. Melanoma Manag 2017;4(1):13-37. https://doi.org/10.2217/mmt-2016-0022

22. Mar V, Wolfe R, Kelly JW. Predicting melanoma risk for the Australian population. Australas J Dermatol 2011;52(2):109-116. https://doi.org/10.1111/j.1440-0960.2010.00727.x

23. Heard AR, Coventry BJ, Milanowski B, Taylor D. The geography of melanoma in South Australia. Aust N Z J Public Health 2009;33(2):105-108. https://doi.org/10.1111/j.1753-6405.2009.00354.X

24. Central Intelligence Agency. Australia-Oceania: Australia. The World Fact Book. https://www.cia.gov/ library/publications/the-world-factbook/geos/as.html (accessed 15 May 2018).

25. Biddle N. Census 2016 reveals Australia is becoming much more diverse - but can we trust the data? The Conversation. http://theconversation.com/census-2016-reveals-australia-is-becoming-much more-diverse-but-can-we-trust-the-data-79835 (accessed 15 May 2018).

26. Statistics South Africa. Migration dynamics in South Africa: Census 2011. http://www.statssa.gov.za/ publications/Report-03-01-79/Report-03-01-792011.pdf (accessed 31 May 2018).

27. Statistics South Africa. Census 2011. http://www.statssa.gov.za/publications/P0302/P03022006.pdf (accessed 31 May 2018)
28. Geodatos. Co-ordinates for South Africa. https://www.geodatos.net/en/coordinates/south-africa/ (accessed on 5 April 2018).

29. Coovadia H, Jewkes R, Barron P, Sanders D, McIntyre D. The health and health system of South Africa: Historical roots of current public health challenges. Lancet 2009;374(9692):817-834. https://doi. org/10.1016/S0140-6736(09)60951-X

30. Austoker J. Melanoma: Prevention and early diagnosis. BMJ 1994;308(6945):1682-1686. https://doi. org/10.1136/bmj.308.6945.1682

31. Fernandez-Flores A, Cassarino DS. Histopathological diagnosis of acral lentiginous melanoma in early stages. Ann Diagn Pathol 2016;26:64-69. https://doi.org/10.1016/j.anndiagpath.2016.08.005

32. Phan A, Touzet S, Dalle S, Ronger-Savle S, Balme B, Thomas L. Acral lentiginous melanoma: A clinicoprognostic study of 126 cases. Br J Dermatol 2006;155(3):561-569. https://doi.org/10.1111/ j.1365-2133.2006.07368.x

33. De Wet J, Tod B, Visser WI, Jordaan HF, Schneider JW. Clinical and pathological features of acral melanoma in a South African population: A retrospective study. 2018;108(9):777-781. https://doi. org/10.7196/SAMJ.2018.v108i9.13435

34. Lodder J, Simson W, Becker P. Malignant melanoma of the skin in black South Africans: A 15-year experience. S Afr J Surg 2010;48(3):76-79.

35. Swan MC, Hudson DA. Malignant melanoma in South Africans of mixed ancestry: A retrospective analysis. Melanoma Res 2003;13(4):415-419. https://doi.org/10.1097/01.cmr.0000056243.56735.e6

36. Postow MA, Hamid O, Carvajal RD. Mucosal melanoma: Pathogenesis, clinical behavior, and management. Curr Oncol Rep 2012;14(5):441-448. https://doi.org/10.1007/s11912-012-0244-x

Accepted 4 September 2018. 